\title{
Erratum to: Aryl hydrocarbon receptor/ cytochrome P450 1A1 pathway mediates breast cancer stem cells expansion through PTEN inhibition and $\beta$-Catenin and Akt activation
}

Abdullah Al-Dhfyan ${ }^{1,2}$, Ali Alhoshani ${ }^{1}$ and Hesham M. Korashy ${ }^{1 *}$

\section{Erratum}

After the publication of this work [1] an error was noticed in the legends for Figs. 5 and 9. The word 'cell sorter' should be deleted from the legend of Fig. 5 in line 3 and the last line. In the legend of Fig. 9 the word 'cell sorter' should be deleted from line 7 .

The original article was corrected.

\begin{abstract}
Author details
'Department of Pharmacology and Toxicology, College of Pharmacy, King Saud University, P.O. Box 2457, Riyadh 11451, Saudi Arabia. ${ }^{2}$ Stem Cell \&

Tissue Re-Engineering, King Faisal Specialist Hospital and Research Center, Riyadh 11211, Saudi Arabia.
\end{abstract}

Received: 10 March 2017 Accepted: 10 March 2017

Published online: 24 March 2017

\section{Reference}

1. Al-Dhfyan A, Alhoshani A, Korashy HM. Aryl hydrocarbon receptor/ cytochrome P450 1A1 pathway mediates breast cancer stem cells expansion through PTEN inhibition and $\beta$-Catenin and Akt activation. Mol Cancer. 2017;16:14.

\footnotetext{
* Correspondence: hkorashy@ksu.edu.sa

'Department of Pharmacology and Toxicology, College of Pharmacy, King Saud University, P.O. Box 2457, Riyadh 11451, Saudi Arabia
} 